\title{
Comprehensive Evaluation of Virulence and Resistance Data: A New Analysis Tool
}

Gabriel A. Schachtel, Biostatistik am FB09, Justus-Liebig University of Giessen, Germany; Amos Dinoor, Department of Plant Pathology and Microbiology, the Robert H. Smith Faculty of Agriculture, Food and the Environment, Hebrew University of Jerusalem, Rehovot, Israel; Antje Herrmann, Institute of Crop Science and Plant Breeding, Christian-Albrechts University of Kiel, Germany; and Evsey Kosman, Institute for Cereal Crops Improvement, the George S. Wise Faculty of Life Sciences, Tel-Aviv University, Israel

\begin{abstract}
Schachtel, G. A., Dinoor, A., Herrmann, A., and Kosman, E. 2012. Comprehensive evaluation of virulence and resistance data: A new analysis tool. Plant Dis. 96:1060-1063.

The functioning and features of the new software package VAT (Virulence Analysis Tool) are introduced. VAT provides a range of methods for the analysis of plant pathosystems. The techniques are applicable to other binary data sets that are organized in large two-way tables, e.g., molecular marker data. The main features are data entry, descriptive tools, and inference statistics by resampling. About 50 well-established or newly developed indices allow a detailed diversity analysis of sex-

ually and asexually reproducing populations. VAT facilitates a comprehensive, effective, and logically consistent evaluation and presentation of virulence and resistance data. A translation option simplifies the comparison of results from differently coded pathotypes. The software package comes with a detailed manual and is freely available on the internet at tau.ac.il/lifesci/departments/plant_s/members/kosman/VAT. html and at va-tipp.de.
\end{abstract}

Phenotypic and genetic characterization of plants and pathogens is used in many areas of plant pathology. In plant epidemiology, compositions of pathogen as well as host populations affect disease dynamics. Resistance spectra are fundamental for the development of new host cultivars. The virulence of pathogens is vital for the early detection of new virulent pathogen phenotypes. All of these activities share the same need to characterize pathogens and/or hosts. Virulence (and resistance) tests are one common and widely used method to perform this task. They generate experimental data that are organized in large two-way tables (e.g., differential hosts in columns, pathogen isolates in rows). In the past, several computer programs were designed specifically for this kind of data. VIRULA by Welz and Ellmer (36), HaGiS by Herrmann et al. (8), and KOIND by Kosman (11) each emphasize only selected aspects of the data. Often the analysis is supplemented with additional, more general software packages, such as NTSYS by Rohlf (26) or Arlequin by Excoffier et al. (4).

The lack of a user-friendly, comprehensive tool for the efficient and logically consistent evaluation and presentation of virulence and resistance data prompted the authors to gather and implement a suitable set of analytic procedures for this type of experimental data into one cohesive software package. This virulence analysis tool (VAT) is intended to assist the entire process of data management and evaluation: data entry, various exploratory and inference statistical steps, and presentation of data and results. We included about 50 different indices, many well-known, and also some recent and newly developed coefficients (Table 1). Providing convenient access to a broad range of methods may help researchers to uncover concealed information from the data and allow for a more

Corresponding author: Evsey Kosman,

E-mail: kosman@post.tau.ac.il

Accepted for publication 17 February 2012.

http://dx.doi.org/10.1094/PDIS-02-12-0114-SR

(C) 2012 The American Phytopathological Society exhaustive data evaluation. This paper describes the functioning and main features of VAT.

Different race nomenclatures impede the communication among plant pathologists. Comparisons among published results are often cumbersome, because they are based on different differential sets and - to make things worse-are expressed in distinct mathematical notations. At least three pathotype nomenclature codes are currently in use. The first and oldest is HGB, the Habgood binary-decimal code (7); two others are Gilmour's octal triplets (GMO) (6) and Roelfs/McVey hexadecimals (RMH) (24). All three pathogenic race codes are in common use $(1,29,31)$. Some authors even combine two codes for their nomenclature, e.g., Liebenberg and Pretorius (16).

Past attempts to agree on one pathotype naming system (at least for specific pathogens) are numerous. However, until now none could considerably reduce or eliminate the prevalent Babylonian speech confusion. One promising attempt was made recently by an international group of researchers from Africa, Asia, Australia, and North America reported in a paper vividly titled "Race nomenclature systems: Can we speak the same language?" (5). Pathologists will need to assemble a unified well-structured (extendable) and meaningful core set of differentials; no software can do their job. But with respect to competing mathematical codes, such as HGB, GMO, and RMH, a convenient translation program can at least ease the problem of sharing and comparing differently coded results. We therefore included such a conversion module in VAT.

\section{The virulence analysis tool "VAT"}

VAT is a computer program for processing pathogenicity and resistance data that are organized in large, two-way tables. While VAT is primarily adapted to the analysis of virulence data of pathogen populations and of resistance data of host populations, it can also be applied to molecular marker data, according to Kosman and Leonard (14). VAT combines a comprehensive compilation of effective methods for data evaluation and presentation in one consistent and user-friendly software package. The package offers the following features:

- Basic routine steps of entry and preparation of experimental data, their transformation and dichotomization, identifica- 
tion and listing of phenotypes in all common race nomenclatures.

- Characterization of isolate and host samples, e.g., by phenotype distribution, virulence (resistance) frequencies and complexities, associations, diversities, and distances, displayed in tables, and by indices.

- Bootstrap estimates of means and variances for diversity, distance, and other parameters of sexually and asexually reproducing populations.

- Compatible output that can be easily transferred to other packages for additional analyses, e.g., PCA, clustering, or dendrograms. VAT renders instant and direct transfer of information to and from MS Excel.

The intrinsic duality of the pathogen-host relationships demands two distinct but analogous types of data evaluation, namely virulence and resistance analyses. If the given data consist of virulence reactions observed with respect to a differential set of host plants, then the VAT-option "Virulence Analysis" provides a whole system of methods. If instead the data originate from resistance reactions of host plants to a set of pathotypes, then the option "Resistance Analysis" will do the job. In both situations, the VAT Main Window offers the following applications: (a) Data entry, (b) Resampling and Coding, (c) Descriptive Statistics, and (d) Inferential Statistics.

\section{Data entry}

This application can perform three kinds of operations: (i) creating new or modifying existing differential sets; (ii) entering new experimental data for analysis (binary or any other numerical assessment scale and the three common race codes HGB, GMO, and $\mathrm{RMH}$ are accepted as data format); and (iii) access to existing data files (system-generated ".vat" files or conventional ".txt"-ASCII files) for editing and validation.

Entered data, experimental design specifications, and comments are stored in VAT for further use, and may also be saved as ASCII or Excel files.

\section{Re-sampling and coding}

As the application's name indicates, it serves two crucial tasks. The "coding" part deals with dichotomization of experimental data, i.e., the translation of nonbinary data into vectors of zeros (absent) and ones (present). To this end, the user will be prompted to devise a cut-off value. For example, cereal rust reactions are commonly coded on a scale of 0 to 4 , in which infection types of 0 to 2 are considered to indicate resistance and 3 or 4 to indicate susceptibility, so that the cut-off value should be 2 . These same issues, relating to the decision where to draw the line between resistance/avirulence and susceptibility/virulence, arise for many other host-pathogen systems. The conversion step is an essential precondition for further analysis, because all subsequent data processing of VAT - descriptive or inferential-operates only on binary data. The coding part handles also the translation to and from the three race codes (HGB, GMO, and $\mathrm{RMH}$ ). The re-sampling part, on the other hand, generates new computer-drawn random samples from the original (dichotomized) data set. The number and size of the generated pseudo-samples can be set by the user. These random samples are the foundation for subsequent estimates of bias and dispersion of any coefficient of interest. They are therefore an indispensable prerequisite for any inferential statistics in VAT.

While the described applications "Data entry" and "Re-sampling and coding" fulfill mainly preparatory functions, the pivotal components of VAT are the two statistical applications "Descriptive statistics" and "Inferential statistics", which provide a broad range of useful measures and indices to help identify and present the most prominent characteristics of the data. Over 50 different approaches can be applied (Table 1), reflected in a collection of 46 different formulas, as listed in the Appendix of the VAT manual. The program allows for all suitable indices to be calculated based on each of three commonly used dissimilarity measures (simple mismatch, Jaccard, and Dice). VAT separates the statistical analysis into two major application modules.

\section{Descriptive statistics}

This application deals with the original data sets observed in the experiment, but in dichotomized form. Based on these samples, all appropriate individual and population parameters are calculated in order to detect and describe the most prominent characteristics of the data (Fig. 1). The results are presented by means of tables and indices.

\section{Inferential statistics}

In contrast to the former "Descriptive statistics" tool, the "Inferential statistics" application performs its calculations not directly on the original data but on corresponding computer-generated pseudo-random samples drawn independently with replacement from the dichotomized observations. This makes it possible to assess inferential conclusions, e.g., to assign statistical significance or confidence intervals to the sample parameters.

\section{Intra- and inter-population analyses}

Many powerful concepts were developed in the past to characterize and compare virulence data on the inter- and intra-popula-

Table 1. Analyses, coefficients, and measures implemented in the VAT software

\begin{tabular}{|c|c|c|}
\hline & Index/measure & Reference \\
\hline \multicolumn{3}{|l|}{ Within populations } \\
\hline \multirow{2}{*}{$\begin{array}{l}\text { Pairwise dissimilarity } \\
\text { of individuals }\end{array}$} & $\begin{array}{l}\text { Simple mismatch coefficient } \\
\text { Jaccard dissimilarity }\end{array}$ & $14,15,32$ \\
\hline & Dice dissimilarity & $3,14,21$ \\
\hline \multirow{3}{*}{$\begin{array}{l}\text { Characterization of } \\
\text { binary loci }\end{array}$} & Allele frequencies & \\
\hline & Correlation between alleles & 13 \\
\hline & $\varphi-$ association between alleles & 33 \\
\hline \multirow{10}{*}{$\begin{array}{l}\text { Characterization of } \\
\text { individuals }\end{array}$} & Phenotype frequencies & \\
\hline & Individual complexity & 2 \\
\hline & Average individual complexity & 2 \\
\hline & Average phenotype complexity & 2 \\
\hline & Relative individual complexity & 13 \\
\hline & $\begin{array}{l}\text { Average relative complexity of } \\
\text { individuals }\end{array}$ & \\
\hline & $\begin{array}{l}\text { Average relative complexity of } \\
\text { phenotypes }\end{array}$ & \\
\hline & Individual uniformity & 13 \\
\hline & Sample uniformity & \\
\hline & Average phenotype uniformity & \\
\hline \multirow{10}{*}{$\begin{array}{l}\text { Overall diversity } \\
\text { estimates }\end{array}$} & Average difference $^{\mathrm{a}}$ & 15 \\
\hline & Kosman diversitya & 10,15 \\
\hline & Gleason richness & 2,23 \\
\hline & Simpson diversity & 30 \\
\hline & Stoddart diversity & 34,35 \\
\hline & Shannon-Wiener entropy & 27 \\
\hline & Evenness & 28 \\
\hline & Normalized Shannon diversity & 2,15 \\
\hline & Nei diversity & 12,19 \\
\hline & $K$-diversity & 17 \\
\hline \multicolumn{3}{|l|}{ Between populations } \\
\hline \multirow[t]{2}{*}{$\begin{array}{l}\text { Comparison of } \\
\text { phenotypes }\end{array}$} & $\begin{array}{l}\text { Common phenotypes and their } \\
\text { frequencies }\end{array}$ & \\
\hline & $\begin{array}{l}\text { Dissimilarity between phenotypes } \\
\text { from two populations }{ }^{\mathrm{b}}\end{array}$ & \\
\hline \multirow[t]{8}{*}{ Distance estimates } & Distance of average differences $\mathrm{a}^{\mathrm{a}}$ & 15 \\
\hline & Kosman distance ${ }^{\mathrm{a}}$ & 10,15 \\
\hline & Rogers distance & 25 \\
\hline & Nei minimum genetic distance & 15,18 \\
\hline & Nei standard genetic distance & 18,20 \\
\hline & $\begin{array}{l}\text { Normalized squared Euclidean } \\
\text { distance (squared average } \\
\text { distances) }\end{array}$ & 32 \\
\hline & Nei differentiation coefficient & 19,37 \\
\hline & Mean character difference & 32 \\
\hline
\end{tabular}

${ }^{a}$ Diversity and distance estimates are calculated with regard to the simple mismatch, Jaccard and Dice dissimilarities.

b Simple mismatch, Jaccard and Dice dissimilarities. 
tion levels $(10,15)$. Accordingly, both statistical modules (Descriptive and Inferential statistics) are subdivided into a "within-" and a "between-" population section.

Within is comprised of a series of analyses that are applied separately to each population, allowing its characterization by (i) frequency of phenotypes, (ii) virulence complexity of phenotypes, (iii) mutual dissimilarity of individuals, (iv) virulence frequencies, (v) the pair-wise association of differentials with respect to their virulence-avirulence pattern, and (vi) the withinpopulation diversity parameters calculated in terms of 14 different coefficients.

Between consists of a series of analyses of pair-wise comparisons of populations, which were studied with respect to the same differential set. It (i) compares the phenotypes of any pair of populations, providing dissimilarity between them, (ii) displays the phenotypes common to all the populations included, listing their frequencies in each population, (iii) supplies the virulence frequencies on differentials for all the included populations, and (iv) calculates the between-populations distances according to 11 different indices.

\section{Automated guidance}

We regarded it as imperative for a successful interactive analysis tool such as VAT, to provide the user at any step with as much automated support by the program as possible. Especially, the large number of different methods, options, and coefficients implemented in VAT may confuse and overwhelm the user.

Several provisions were taken to avoid such potential "overstraining". The layout of the program and its numerous windows and sheets was designed in a way that the next possible step is displayed only after the necessary step before has been concluded. The constitutive applications in the main window are arranged from left to right, indicating the best sequence of progression. An extensive and sophisticated set of pop-up boxes with comments, recommendations, error-messages, and other warnings appears automatically at many points. It pilots the user through difficult situations and reminds at suitable occasions about potential pitfalls, mistakes, or even a lurking loss of data. Self-explanatory labeling of tags, buttons, sheets, and windows provides further direction and guidance.

Finally, the VAT manual gives detailed instructions on all functionalities of the program, illustrated by examples and screen shots. It is designed to serve a dual purpose, as an introductory tutorial and as a quick-reference book. The elaborate Appendix is organized into five sections (Dissimilarity between individuals; Comparison of differentials; Characterization of individuals; Diversity within and among populations; and Re-sampling) and provides formulas for all implemented coefficients.

\section{Software availability}

VAT is freely available and can be downloaded with corresponding manuals at tau.ac.il/lifesci/departments/plant_s/members/ kosman/VAT.html and va-tipp.de. VAT needs a programming environment of the Microsoft .NET Framework, an integral Windows component. Therefore, .NET Framework should be installed on the user's PC. A supplementary software "VA-View", which introduces a new kind of pictorial display of phenotypes that requires no familiarity with any mathematical nomenclature, can be downloaded at va-tipp.de.

\section{Conclusions}

The analysis of pathosystems generates binary data in a twoway-tabled structure. Our software package supports all routine steps of data entry and provides guidance and tools for a comprehensive evaluation. This systematic approach will substantially improve the analysis, increase the understanding of collected data, and possibly help extract more and otherwise concealed information. The coexistence of competing naming systems is an unresolved problem. Bridging the disparities in nomenclatures would certainly add precision to international efforts in surveillance and control of plant pathogens (22).

\section{Acknowledgments}

We thank Iliya Bulaevsky, Ariel Gilad, Boris Lvovsky, Shir Hofstetter, Lothar Langer, and Santani Teng for their valuable help with programming and manuals. This work was supported by the German-Israeli Foundation for Scientific Research and Development (GIF), Research Grant No. I-744-121.12/2002. Contribution of the COST860 (SUSVAR) network in the framework for European Cooperation in Science and Technology and partial financial support of the Lieberman-Okinow and Colton foundations (Tel Aviv University) to E. Kosman are also gratefully acknowledged.

\section{Literature Cited}

1. Afshari, F. 2008. Prevalent pathotypes of Puccinia striiformis f.sp. tritici in Iran. J. Agric. Sci. Technol. 10:67-78.

2. Andrivon, D., and de Vallavieille-Pope, C. 1995. Race diversity and complexity in selected populations of fungal biotrophic pathogens of cereals. Phytopathology 85:897-905.

3. Dice, L. R. 1945. Measures of the amount of ecologic association between species. Ecology 26:297-302.

4. Excoffier, L., Laval, G., and Schneider, S. 2005. Arlequin (version 3.0): An integrated software package for population genetics data analysis. Evol. Bioinform. Online 1:47-50.

5. Fetch, T., Jin, Y., Nazari, K., Park, R., Prashar, M., and Pretorius, Z. 2009. Race nomenclature systems: Can we speak the same language? Pages 61-64 in: Proceedings of Oral Papers and Posters, Technical Workshop, BGRI, Cd.

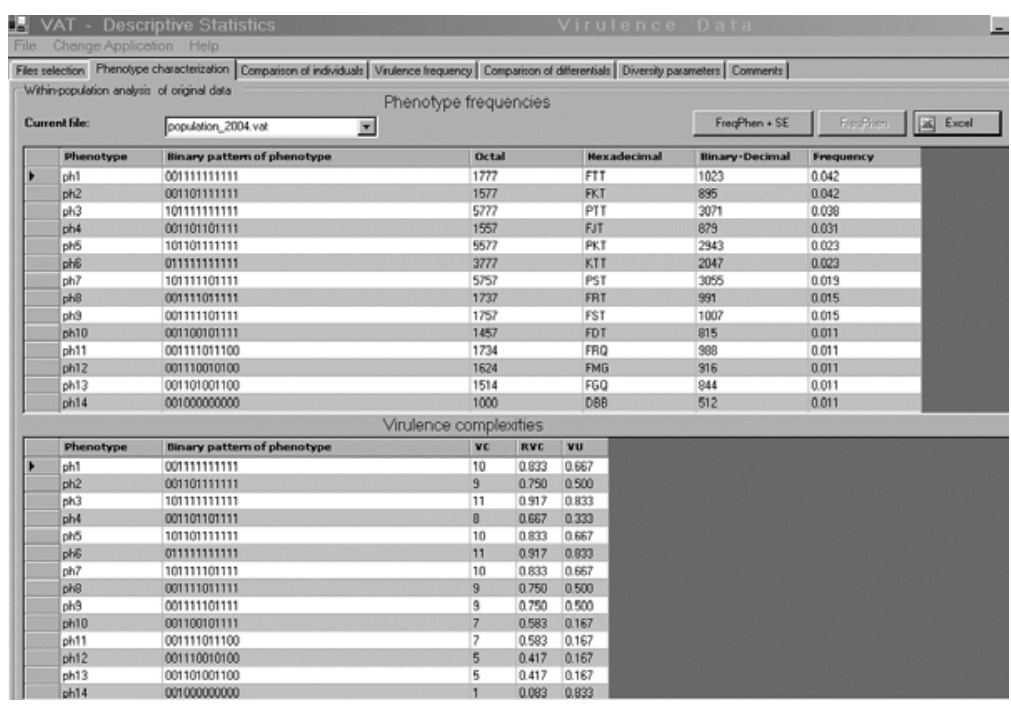

Fig. 1. Phenotype characterization window. Upper table: observed phenotypes (in binary, in GMO, RMH, and HGB code) and their frequencies. Bottom table: Virulence Complexity (VC), Relative Virulence Complexity (RVC), and Virulence Uniformity (VU). For corresponding formulas see VAT manual. 
Obrego'n, Sonora Mexico. R. McIntosh, ed.

6. Gilmour, J. 1973. Octal notation for designating physiologic races of plant pathogens. Nature 242:620.

7. Habgood, R. M. 1970. Designation of physiological races of plant pathogens. Nature 227:1268-1269.

8. Herrmann, A., Löwer, C. F., and Schachtel G. A. 1999. A new tool for entry and analysis of virulence data for plant pathogens. Plant Pathol. 48:154-158.

9. Jaccard, P. 1908. Nouvelles rescherches sur la distribution florale. Bull. Soc. Vaud. Sci. Nat. 44:223-270.

10. Kosman, E. 1996. Difference and diversity of plant pathogen populations: A new approach for measuring. Phytopathology 86:1152-1155.

11. Kosman, E. 2001. KOIND - package of programs for calculating diversities within and between populations. Pages 195-197 in: Sustainable systems of cereal crop protection against fungal diseases as the way of reduction of toxin occurrence in food webs, Proceedings. L Tvarůžek, ed. Agricultural Research Institute Kroměříž.

12. Kosman, E. 2003. Nei's gene diversity and the index of average differences are identical measures of diversity within populations. Plant Pathol. 52:533535 .

13. Kosman, E. 2003. Measure of multilocus correlation as a new parameter for study of plant pathogen populations. Phytopathology 93:1464-1470.

14. Kosman, E., and Leonard, K. J. 2005. Similarity coefficients for molecular markers in studies of genetic relationships between individuals for haploid, diploid, and polyploid species. Molecular Mol. Ecol. 14:415-424.

15. Kosman, E., and Leonard, K. J. 2007. Conceptual analysis of methods applied to assessment of diversity within and distance between populations with asexual or mixed mode of reproduction. New Phytol. 174:683-696.

16. Liebenberg, M. M., and Pretorius, Z. A. 2011. Pathogenic diversity in and sources of resistance to Uromyces appendiculatus in Southern Africa. J. Phytopathol. 159:287-297.

17. Manisterski, J., Eyal, Z., Ben-Yehuda, P., and Kosman, E. 2000. Comparative analysis of indices in the study of virulence diversity between and within populations of Puccinia recondita f. sp. tritici in Israel. Phytopathology 90:601-607.

18. Nei, M. 1972. Genetic distance between populations. Am. Naturalist 106:283-292.

19. Nei, M. 1973. Analysis of gene diversity in subdivided populations. Proc. Natl. Acad. Sci. USA 70:3321-3323.

20. Nei, M. 1978. Estimation of average heterozygosities and genetic distance from a small number of individuals. Genetics 89:583-590.
21. Nei, M., and Li, W. H. 1979. Mathematical model for studying genetic variation in terms of restriction endonucleasis. Proc. Natl. Acad. Sci. USA 76:5269-5273.

22. Park, R., Fetch, T., Hodson, D., Jin, Y., Nazari, K., Prashar, M., and Pretorius, Z. 2011. International surveillance of wheat rust pathogens: Progress and challenges. Euphytica 179:109-117.

23. Pielou, E. C. 1974. Population and Community Ecology. Principles and Methods. Gordon and Breach, New York.

24. Roelfs, A. P., and McVey, D. V. 1973. Races of Puccinia graminis f. sp. tritici in the USA during 1972. Plant Dis. Rep. 57:880-884

25. Rogers, J. S. 1972. Measures of genetic similarity and genetic distance. Pages 145-153 in: Studies in Genetics VII. University of Texas Publ. 7213 Austin.

26. Rohlf, F. J. 2000. NTSYS 2.1 numerical taxonomy and multivariate analysis system. Exeter Publ., New York.

27. Shannon, C. E., and Weaver, W. 1949. The Mathematical Theory of Communication. University of Illinois Press, Urbana.

28. Sheldon, A. L. 1969. Equitability indices: Dependence on the species count. Ecology 50:466-467.

29. Silvar, C., Flath, K., Kopahnke, D., Gracia, M. P., Lasa, J. M., Casas, A. M. Igartua, E., and Ordon, F. 2011. Analysis of powdery mildew resistance in the Spanish barley core collection. Plant Breed. 130:195-202.

30. Simpson, E. H. 1949. Measurement of diversity. Nature 163:688.

31. Singh, R. P., Hodson, D. P., Huerta-Espino, J., Jin, Y., Bhavani, S., Njau, P., Herrera-Foessel, S., Singh, P. K., Singh, S., and Govindan, V. 2011. The emergence of Ug99 races of the stem rust fungus is a threat to world wheat production. Annu. Rev. Phytopathol. 49:465-481.

32. Sneath, P. A., and Sokal, R. R. 1973. Numerical Taxonomy. W. H. Freeman Co., San Francisco.

33. Sokal, R. R., and Rohlf, F. J. 1995. Biometry. W. H. Freeman Co., New York.

34. Stoddart, J. A. 1983. A genotypic diversity measure. J. Hered. 74: 489-490.

35. Stoddart, J. A., and Taylor, J. F. 1988. Genotypic diversity: Estimation and prediction in samples. Genetics 118:705-711.

36. Welz, G., and Ellmer, J. 1991. VIRULA - A computer programme to process virulence data. Pages 123-133 in: Integrated Control of Cereal Mildews: Virulence Patterns and Their Change. J. H. Jørgensen, ed. Risoe National Laboratory, Roskilde, Denmark.

37. Wright, S. 1951. The genetic structure of populations. Ann. Eugenics 15:323-354. 